\title{
Resenha, a crítica do jornal
}

\author{
Lia Seixas \\ http://orcid.org/0000-0002-4459-6729 \\ Emiliana Carvalho' \\ https://orcid.org/0000-0002-6510-3700 \\ I - UFBA. \\ Salvador (BA), Brasil
}

Resumo: Este artigo defende que a resenha é a crítica do jornal, fundada no campo jornalístico, nascida juntamente com os princípios e valores do jornalismo moderno. Operamos a proposta de critérios de definição de gênero: lógica enunciativa, força argumentativa, identidade discursiva e potencialidades do mídium (SEIXAS, 2009). Observamos que as regularidades dos critérios auxiliam a compreender o gênero, mas uma ação relativamente estável deve ser confrontada com as propriedades da instituição da qual faz parte. Atualidade, periodicidade, objetividade (GROTH, 2011; SCHUDSON, 2008, 2011; FRANCISCATO, 2003) agem na constituição da resenha, voltada para o atual e o novo e de predominância argumentativa (ADAM, 1992).

Palavras-chave: resenha; crítica jornalística; gênero jornalístico.

Abstract: Review, the newspaper critique. This article argues that the review is the cultural critique in newspapers, founded on the journalistic field, which came into being along with the principles and values of modern journalism. We operate the proposal of criteria of definition of gender: enunciative logic, argumentative force, discursive identity and potentialities of the medium (SEIXAS, 2009). We observe that the regularities of the criteria help to understand the genre, but a relatively stable action must be confronted with the properties of the institution of which it is a part. Currency, periodicity, objectivity (GROTH, 2011, SCHUDSON, 2008, 2011, FRANCISCATO, 2003) act in the constitution of the review, oriented to the current and the new and predominantly argumentative (ADAM, 1992).

Keywords: review; newspaper critique; journalistic genre.

\section{Da crítica à resenha}

A resenha jornalística é crítica ou matéria do campo jornalístico? Qual a diferença entre crítica e resenha? Apesar de ser publicada nos jornais e revistas desde o século XVIII, a resenha ainda carece análise. Mesmo diante das transformações ocorridas no campo jornalismo pós-industrial (DEUZE, 2016; ANDERSON, BELL, SHIRKLY, 2013) - a resenha continua ocupando as páginas dos cadernos e seções de cultura dos principais jornais tradicionais e inspirando novas propostas editoriais, como a Quatro Cinco Um, em 2017. 
No Brasil, uma das mais utilizadas definições de resenha vem de José Marques de Melo: "O gênero jornalístico que se convencionou chamar de resenha corresponde a uma apreciação das obras-de-arte ou dos produtos culturais, com a finalidade de orientar a ação dos fruidores ou consumidores" (MARQUES DE MELO,1994, p.125). Nessa afirmação, o pesquisador reúne dois pontos importantes: primeiro, insere a resenha no campo jornalístico; segundo, identifica uma de suas finalidades: orientar. Debruça-se sobre a estrutura da resenha, ao passo que a inserção no campo jornalístico é investigada apenas sob o critério de função da composição.

Nos produtos jornalísticos, o termo crítica define e marca essas composições jornalísticas. "O termo resenha ainda não se generalizou no Brasil, persistindo o emprego da palavra crítica para significar as unidades jornalísticas que cumprem aquela função e crítico para designar quem as elabora" (MARQUES DE MELO, 1994, p.126). Esse hábito, por assim dizer, vem justamente de suas origens, relacionadas à crítica literária, e se mantém até então na cultura jornalística. O termo crítica carrega uma significação simbólica que mantém e congrega em si um sentido de "legitimidade cultural" (BOURDIEU, 2007, p.155).

Os poucos estudos sobre resenha e crítica estão localizados em áreas diversas ao campo do jornalismo, com ênfase na Linguística Aplicada. A partir da busca na Biblioteca Digital Brasileira de Teses e Dissertações (BDTD), no Banco Digital de Teses e Dissertações da Capes, nas revistas Galáxia, MATRIZes, FAMECOS e RBCC, anais da Intercom e da SBPJor, além de uma investigação geral com as palavras-chave resenha, resenha crítica, resenha jornalística e crítica jornalística, chegamos a 35 trabalhos que fazem referência ao gênero. Destes, 16 dissertações, 4 teses e 1 artigo. Os trabalhos associam, em sua maioria, as análises à obra de algum escritor, artista, a alguma expressão artística ou produto cultural e midiático. Focalizam no caráter conceitual da resenha jornalística apenas 2 teses, 2 dissertações e 1 artigo. Ao final, notamos que, ainda que a resenha jornalística encontre diversas denominações em diferentes autores (resenha crítica, crítica jornalística, crítica militante de jornal, crítica de jornal, e crítica periodística), ao contrário da crítica literária, a finalidade acaba sendo a mesma: orientar o leitor-consumidor de livros e outros produtos culturais da atualidade.

Assim, o trabalho propõe uma definição de resenha jornalística por meio da comparação de 36 textos sobre literatura: 1) Doze com chapéu crítica do caderno de cultura diário Ilustrada do website noticioso de referência com circulação nacional Folha de S. Paulo; 2) Doze resenhas literárias com chamadas na capa da recém-lançada revista especializada em resenhas Quatro Cinco Um publicadas entre maio e outubro de 2017; e 3) Doze críticas literárias do renomado Álvaro Lins no cotidiano carioca Correio da Manhã (RJ), década de 1940. O corpus selecionado representa a comparação entre: o período em que ainda havia a publicação dos tradicionais rodapés de crítica literária nas páginas principais de periódico cotidiano de grande circulação (Correio da Manhã - RJ/1940), um produto contemporâneo especializado (Quatro Cinco Um) e um caderno de jornal tradicional com seção exclusiva para veiculação de críticas de livros (Ilustrada). 

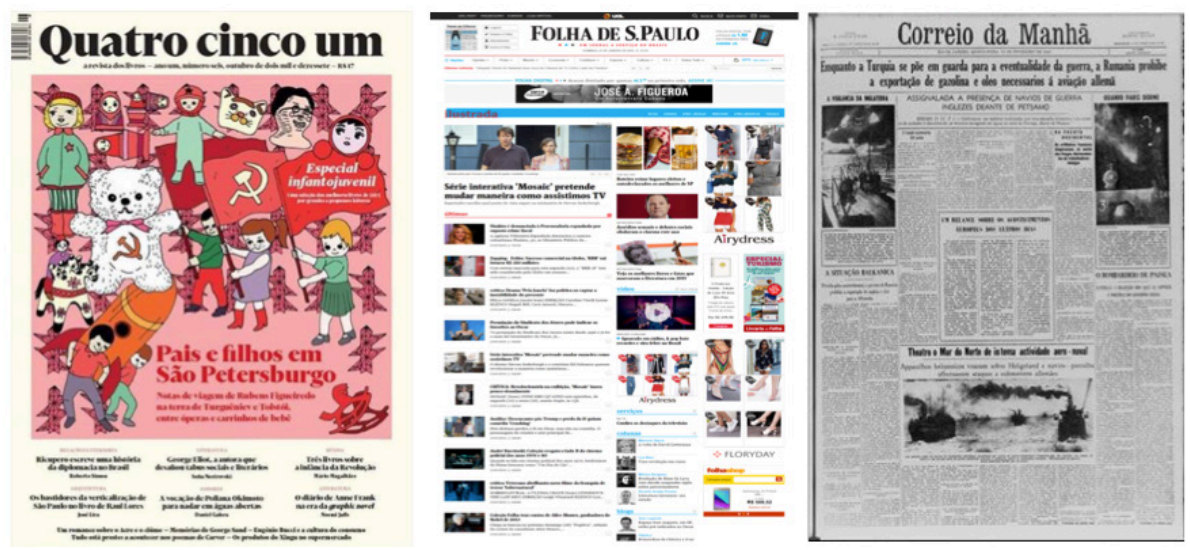

Fig. 1. À esquerda, a capa da revista Quatro Cinco Um, de 08/17. À direita, $1^{\text {a }}$ página do Correio da Manhã (RJ), em 14/09/1940.

Centralizada, homepage do llustrada, em 16/01/17.

Este artigo pretende examinar conceitualmente a resenha. Além de podermos realizar um teste metodológico com a proposta, expandimos a análise para o campo jornalístico. Analisamos primeiro as propriedades do jornalismo (GROTH, 2011; SCHUDSON, 2008, 2011; FRANCISCATO, 2003) e depois examinamos cada texto a partir da proposta de critérios de definição de gêneros jornalísticos de Seixas (2009). A partir do princípio de que gênero jornalístico deve ser considerado enunciação relativamente estável, os gêneros discursivos encarnam o processo de comunicação, portanto, além de suas organizações textuais, devem ser analisados segundo dimensões extralinguísticas, inclusive funções, valores e princípios da instituição que os abriga. O estudo sugere quatro critérios de definição:

1. lógica enunciativa, que se dá na relação entre objetos de realidade (objetos de acordo e de desacordo), compromissos realizados (com a noção de "sequência" de Adam, 1992) e tópicos jornalísticos;

2. força argumentativa, que se dá na relação entre o grau de verossimilhança dos enunciados e o nível de evidência dos objetos de realidade, medida pelos tópicos jornalísticos;

3. identidade discursiva, que se dá na relação entre status (competências) e as dimensões de sujeito comunicante, locutor e enunciador no ato da troca comunicativa;

4. potencialidades do mídium, relacionados aos dispositivos midiáticos, em que apenas algumas características são influentes para as composições (SEIXAS, 2009, p.1-2).

A sequência é entendida como componente textual. Seria um conjunto de unidades típicas básicas que se agrupam de forma heterogênea para formar gêneros 
(BONINI, 1999). Embora a divisão não seja consensual na Linguística Aplicada, Adam dividiu as sequências textuais em cinco tipos: narrativa, argumentativa, descritiva, explicativa (também considerada expositiva por outros autores) e dialogal (ADAM, 1992). Em linhas gerais, a sequência narrativa tem o objetivo de contar uma história; a descritiva, o de apresentar, retratar algo ou alguém; a argumentativa o de convencer; a explicativa, o de esclarecer/entender um fenômeno ou um conceito; a dialogal é voltada para a conversação e a informativa, compartilhar informações. Os gêneros não são compostos apenas por uma sequência textual. Em geral, um único tipo de texto é composto por mais de uma. No entanto, ainda que apresente todas ou quase todas, haverá uma predominância de uma sequência. É essa predominância que buscaremos.

\section{Gênero do jornalismo moderno}

O desenvolvimento da esfera pública burguesa no início do século XVIII está estreitamente ligado ao moderno conceito de crítica literária. Era clara, nessa época, a intersecção entre assuntos que envolviam as culturas literária e política-financeira (EAGLETON, 1991). Havia aí uma crítica social e cultural e os críticos tornaram-se portadores de uma tarefa histórica por meio dos periódicos, por serem capazes de opinar sobre todas as coisas. O jornalismo estava em amplo processo de estabelecimento e o tom literário contribuiu muito para a sua legitimação. Uma engrenagem comercial se formou em torno da produção de periódicos literários e uma relação mercadológica que envolveu a imprensa e as editoras favoreceu a produção em série de obras segundo métodos semi-industriais. A extensão do público resultante da generalização do ensino elementar permitiu às novas classes o acesso ao consumo cultural (BOURDIEU, 2007). Nesse cenário, na Inglaterra no século XVIII, surgiu o crítico profissional' ${ }^{1}$, o reviewer, cuja tarefa, segundo conta Virgínia Woolf, era fazer uma apreciação da literatura corrente, em distinção ao trabalho do crítico que lidaria com o passado e os princípios (WOOLF apud COUTINHO, 1957, p.77-78).

As mudanças sofridas pela atividade crítica e as mudanças no campo jornalístico se inter-relacionam. O jornalismo foi adaptando-se às modificações socioeconômicas, enquanto a alta crítica foi vista como atividade que sofreu prejuízos, pois os escritores passam a escrever para o público. Com isso, o mercado editorial viu-se na necessidade de oferecer mais informações sobre os livros. O novo sistema socioeconômico criou o reviewer tanto quanto criou o jornalismo moderno.

A separação entre fato e opinião está na origem do jornalismo moderno, a ponto de ser considerada uma 'competência de conduta' (GUERRA, 2003). Nessa instituição social reconhecida como jornalismo, interesse público e objetividade se estabilizam como valor (GUTMANN, 2014). Solidificam-se 'rituais estratégicos' (TUCHMAN, 1972), práticas

1 A definição de "crítico profissional" faz referência à atividade dos reviewers (resenhistas). 
de apuração e rotinas produtivas. O ideal da objetividade não só influencia as práticas do jornalista como também se relaciona ao ritmo de produção de um jornal, no que se refere ao cumprimento de prazos. Um campo social (BOURDIEU, 2007; GOMES, 2004) se consolida com funções de informar, investigar, analisar e fórum público (SCHUDSON, 2007), reconhecidas intersubjetivamente. O jornalismo fixa-se como prática social do presente (FRANCISCATO, 2003) com dadas características fundamentais: universalidade, publicização, atualidade, periodicidade (GROTH, 2014).

A periodicidade domina toda a construção e aparelhagem de produção, tempo, intensidade, divisão do trabalho, número, composição, ocupação das máquinas, como também o ritmo da empresa e do seu pessoal (GROTH, 2011, p.165) e incide sobre a linha editorial de maneira a definir o produto. Considera-se que a crítica literária não se submete às demarcações do tempo para sua construção. A resenha, sim. A revista especializada é mensal e, na década de 40, os textos de Álvaro Lins eram publicados todo sábado, assim como o maior número de críticas do Ilustrada. Nos seis meses citados foram 55; nos demais dias da semana variavam de 1 a 7 publicações. Não é perceptível a influência do tempo como fator de pressão sobre as críticas de Álvaro Lins. Havia tempo suficiente para uma leitura e reflexão aprofundadas e havia espaço para uma produção extensa, assim como nas resenhas da Quatro Cinco Um. A pressão do tempo se dá não pela atividade de resenhar, mas pela realidade em si, pela lógica do produto e pelo fato de o repórter com dada cultura jornalística estar submetido às pressões do processo de produção de outras notícias. "A leitura do livro a ser resenhado deve ser feita integralmente. É bem verdade que não é isso que acontece - a imposição dos deadlines para os fechamentos é cruel - e, por isso, muitos fazem apenas um voo rasante sobre a obra" (NINA, 2007, p.52), como observado nas críticas do Ilustrada.

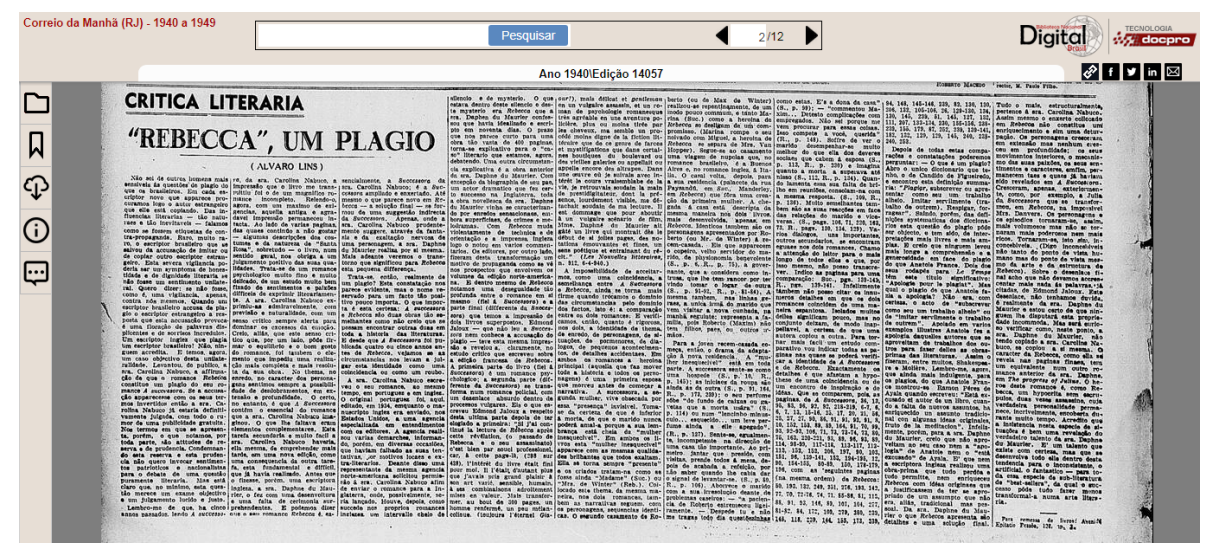

Fig. 2. Rodapé de crítica de Álvaro Lins, em 31/8/1940. 
É possível ver que o regime temporal também influencia no comprimento do texto. Nas amostras do /lustrada observamos que as resenhas são compostas de 9 a 17 parágrafos curtos, de 2 a 7 linhas no máximo, sendo que os textos não ocupam sequer $1 / 4$ do espaço total da página do website noticioso. É um espaço pequeno para um texto pequeno, condizente com o que Afrânio Coutinho (1957) entendia como sendo uma das características do review: uma nota ligeira, efêmera, um comentário sobre os livros do momento. A crítica "Rebecca", um plagio é composta por 7 parágrafos que variam de 16 a 121 linhas cada. Essa tendência se confirma nas demais composições selecionadas de Lins. Notamos, em termos de comparação, que as críticas do /lustrada não ocupam o espaço que uma crítica nos anos de 1940 exigia.

A atualidade é umas das propriedades do jornalismo mais influentes para a concepção de resenha jornalística, compreendida como uma relação puramente temporal e que, no jornal, designa uma característica de intermediar o atual, o presente (GROTH, 2011). Nosso estudo está em consonância com a premissa de que a atualidade é um processo mais amplo de experiência social do tempo (FRANCISCATO, 2003). Um dos fatores que demarcam significativamente a diferença entre crítica literária e resenha jornalística é a relação com o tempo. A produção da crítica literária não está atrelada ao tempo presente, pois não depende constitutivamente do campo no qual o presente é fundamental. "O jornalismo é uma prática social voltada para a produção de relatos sobre eventos do tempo presente. Ao fazer isso, [...] atua de forma privilegiada como reforço de uma temporalidade social, enquanto produtor de formas específicas de sociabilidade" (FRANCISCATO, 2014, p.97). O que se origina no interior desta prática social carrega imediatamente a marca do presente. É o que acontece com a resenha. A relação com a atualidade é evidente, desde a origem como review no século XVIII até a definição de suas finalidades: informar e orientar o público de jornais e revistas sobre os livros do momento (COUTINHO, 1957). Portanto, podemos afirmar que a resenha é o resultado dessa construção viabilizada pela instituição jornalística. É consequência da "necessidade" de pensar, conhecer e consumir apenas o que está acontecendo ou na iminência de acontecer. Além do atual a resenha congrega o novo. Atual porque tem relação com o presente, com o que está sendo lançado agora, é uma relação temporal. Novo porque tem relação com o que era até o momento desconhecido e deixou de ser (GROTH, 2011). Um livro novo, um produto cultural novo representa novidade. Ao contrário, a crítica literária não tem essa preocupação com a atualidade e com a novidade. O que a interessa é o estudo das obras com ênfase na sua avaliação.

\section{Critérios de definição na resenha}

Analisamos as resenhas testando a compreensão de que são uma composição discursiva jornalística com regularidade na lógica enunciativa, força argumentativa, identidade discursiva e propriedades de mídium (SEIXAS, 2009). A lógica enunciativa se 
constitui na relação entre objetos de realidade, tópicos jornalísticos e compromissos realizados pelo ato de linguagem. Os objetos de realidade, matéria-prima do jornalismo, vão além dos fatos e acontecimentos. A proposta divide-os em: 1) objetos de acordo: passíveis de constatação intersubjetiva pela simples presença e também não passíveis de verificação, como verdades de saberes científicos e 2) objetos de desacordo: indefinidos, abstratos, assim como objetos que são o resultado de conexões entre esses objetos. Os tópicos jornalísticos ${ }^{2}$ são lugares comuns (portanto, de conhecimento geral) sobre as relações entre os objetos de realidade compartilhados pelos públicos, que autorizam determinadas conclusões. Os compromissos realizados pelo ato de linguagem constituem o propósito reconhecido do fazer linguístico, ação efetivamente realizada ao se proferir algo (SEIXAS, 2009). Contabilizamos os objetos de acordo e de desacordo das 36 composições. Analisamos as relações de cada objeto com a realidade e os compromissos realizados, não só por proposições, mas por sequências textuais. Um exemplo representativo da análise comparativa está no quadro abaixo:

\begin{tabular}{|c|c|c|}
\hline $\begin{array}{l}\text { 17/08/1940 } \\
\text { Correio da Manhã (RJ) /Crítica } \\
\text { Literária } \\
\text { Unidade e Divisão } \\
\text { Álvaro Lins }\end{array}$ & $\begin{array}{l}\text { 07/2017 } \\
\text { Quatro Cinco Um /Direito } \\
\text { O Petróleo é deles } \\
\text { Octávio L. M. Ferraz }\end{array}$ & $\begin{array}{l}23 / 10 / 2017 \\
\text { Ilustrada /Crítica/Livros } \\
\text { 'Treze Meses Dentro da Tv' relata } \\
\text { sufocante isolamento na Globo } \\
\text { Nelson de Sá }\end{array}$ \\
\hline $\begin{array}{l}\text { "O senhor Octavio de Faria } \\
\text { tem o destino do debate. } \\
\text { Para elle mesmo a sua obra } \\
\text { é uma expressão de lutas } \\
\text { interiores que nasceram com } \\
\text { a sua personalidade e que se } \\
\text { multiplicam dentro da vida. O seu } \\
\text { estado é o de uma permanente } \\
\text { querella. Ninguém, como elle, } \\
\text { aspira tanto à unidade e ao amor. } \\
\text { Ninguém, como elle, se mutilla } \\
\text { tanto em movimentos de divisão, } \\
\text { de lutas, de ódios. Unidade e } \\
\text { divisão: eis o Sr. Octavio Faria. } \\
\text { [...] "Ultrapassar" - isto explica o } \\
\text { sr. Octavio de Faria, é o que há de } \\
\text { dramático, de trágico e de terrível } \\
\text { na sua obra. Vamos desejar que } \\
\text { ultrapasse, que vença os seus } \\
\text { "demônios", que consquiste a } \\
\text { paz, que se reconcilie com o } \\
\text { mundo? Uma solução desta iria } \\
\text { tornal-o feliz, como homem, mas } \\
\text { iria matal-o como escrictor e } \\
\text { como artista. Não: é o contrário } \\
\text { que queremos [...]". [1 } 1^{\circ} \text { parágrafo] }\end{array}$ & $\begin{array}{l}\text { "Mais da metade do petróleo } \\
\text { comercializado em todo o } \\
\text { mundo vem de países em que } \\
\text { a população não tem nenhum } \\
\text { controle sobre os recursos } \\
\text { naturais que possui - ou seja, } \\
\text { nos quais não vigora o princípio } \\
\text { da soberania popular sobre eles. } \\
\text { [3º parágrafo] } \\
\text { O Brasil, como muitos outros } \\
\text { países, ajuda a perpetuar essa } \\
\text { situação iníqua ao satisfazer parte } \\
\text { de suas necessidades de petróleo } \\
\text { (120 milhões de barris por ano) } \\
\text { com importações de países como } \\
\text { Arábia Saudita (quase } 25 \% \text { das } \\
\text { importações) e Guiné Equatorial } \\
\text { (5\%). [4 parágrafo] } \\
\text { [...] } \\
\text { Ao ajudar a extrair e importar } \\
\text { recursos naturais em total } \\
\text { desrespeito ao princípio da } \\
\text { soberania popular, estão } \\
\text { literalmente receptando } \\
\text { recursos roubados da população } \\
\text { e reforçando, assim, a ideia } \\
\text { ultrapassada e inaceitável } \\
\text { do "poder faz o direito". [9 } \\
\text { parágrafo] }\end{array}$ & $\begin{array}{l}\text { [...] } \\
\text { A cena sufocantes da demissão: } \\
\text { "Subi à sala do diretor. Quando } \\
\text { entrei, me deparei com meu } \\
\text { chefe sentado lá. Ouvi do diretor } \\
\text { que eles tinham analisado os } \\
\text { problemas do 'Fantástico' e } \\
\text { chegado à conclusão de que } \\
\text { vários deles passavam por mim. } \\
\text { Ele disse que as pessoas não me } \\
\text { respeitavam, que riam das minhas } \\
\text { sugestões". [7º parágrafo] } \\
\text { Empacotado como um manual } \\
\text { para executivos, o livro chega } \\
\text { então às lições a serem tiradas } \\
\text { da experiência "por que não } \\
\text { deu certo". Entre as respostas } \\
\text { insatisfatórias apareceu esta: "Eu } \\
\text { não escolhi um par de mãos } \\
\text { para beixar, em troca de apoio e } \\
\text { proteção". [8 parágrafo] }\end{array}$ \\
\hline
\end{tabular}

2 Sobre os principais tópicos jornalísticos e compromissos realizados pelo ato de linguagem consultar respectivamente as páginas: 4, 5, 322 e 323 da tese Redefinindo os gêneros jornalísticos: proposta de novos critérios de classificação. Disponível em: http://www.labcom-ifp.ubi.pt/ficheiros/20110818-seixas_ classificacao_2009.pdf. 
Comparando fragmentos das críticas de Lins com as resenhas da Quatro Cinco Um e llustrada observamos que a utilização de objetos de desacordo, abstratos e indefinidos é constante na linguagem do crítico, fortemente metafórica. O enunciado (em negrito) não está calcado na realidade, ou seja, não pode ser comprovado, verificado. São objetos que nascem da percepção, impressão e julgamento do crítico. A linguagem metafórica de Álvaro Lins conduz o leitor para sua avaliação. O jogo de palavras constrói o argumento e faz o leitor tomar conhecimento da opinião e do gosto do crítico sobre a obra por meio das impressões, daí o termo impressionismo que desagrada adeptos de uma crítica fundamentada em métodos e teorias literárias com bases científicas.

Já as resenhas do caderno de cultura e da revista alternam asserção e opinião. Vejamos em: O Petróleo é deles ( ${ }^{\text {a }}$ coluna): há opinião, mas são dados informativos, reais, que permitem o desenvolvimento da argumentação. O resenhista fala de "uma situação iníqua" a partir de dados passíveis de comprovação ( $3^{\circ}$ parágrafo, em negrito), revela com estatísticas que podem ser verificadas o porquê ( $4^{\circ}$ parágrafo, em negrito) e, a partir dos dados expostos, no $9^{\circ}$ parágrafo, opina. No caso de "Trezes Meses Dentro da TV" revela sufocante isolamento na Globo ( $3^{\mathrm{a}}$ coluna) há transcrição de trechos do livro com narrações do próprio autor sobre sua experiência como diretor de um programa televisivo ( $7^{\circ}$ e $8^{\circ}$ parágrafos, em negrito). Acabam funcionando como amostra do conteúdo do livro. É constatável no momento da leitura, mostrando que não é o resenhista quem diz. Pudemos observar a predominância de objetos de desacordo, embora a revista especializada tenha metade de cada. Nos textos analisados de Álvaro Lins há 73\% de objetos de desacordo, enquanto nos textos da Folha de S. Paulo, 53\%.

\begin{tabular}{|l|l|l|}
\hline Produtos & Objetos de acordo & Objetos de desacordo \\
\hline Quatro Cinco Um & $51 \%(147)$ & $49 \%(143)$ \\
\hline Ilustrada/ Folha de S. Paulo & $47 \%(82)$ & $53 \%(94)$ \\
\hline Correio da Manhã (RJ) & $27 \%(121)$ & $73 \%(333)$ \\
\hline
\end{tabular}

Tab. 1. Objetos de realidade

Há alternância entre assertivos e opinativos no texto, mas é importante observar que as informações "estão a serviço" da construção da argumentação ou mesmo da sustentação da opinião. Esse resultado coaduna com a predominância da sequência argumentativa. Um exemplo representativo é o texto abaixo, do caderno Ilustrada: 


\section{CRÍTICA}

De alta voltagem lírica, Frank $\mathrm{O}^{\prime} \mathrm{Hara}$ tem poemas traduzidos

[1 $1^{\circ}$ "Meu Coração Está no Bolso" traz 25 poemas de Frank O'Hara (1926-1966), um dos poetas americanos mais relevantes da segunda metade do século 20. No Brasil, desde os anos 1990, ele vinha sendo traduzido esparsamente, mas esta é a primeira reunião de poemas dele em livro.

$\left[2^{\circ}\right] \mathbf{O}^{\prime}$ Hara costuma ser considerado figura central da chamada Escola de Nova York. $\mathrm{O}$ termo define não um movimento, mas um grupo de poetas-amigos com interesses em comum: o horror ao formalismo estéril dominante na poesia do pós-Guerra, a pintura expressionista abstrata e uma atitude informal e antiacadêmica.

$\left[3^{\circ}\right]$ A poesia de $\mathrm{O}^{\prime} \mathrm{Hara}$, coloquial e de alta voltagem lírica, é tributária de Walt Whitman, do surrealismo e, sobretudo, do lirismo ambiente, do simultaneísmo, dos poemas-passeios e poemas-conversas de Apollinaire. Quer captar o imediato, o aqui-e-agora do poema, numa espécie de zen nova-iorquino.

$\left[4^{\circ}\right]$ Uma de suas marcas registradas é começar o poema precisando o dia, hora, o clima ou local de sua ocorrência, como em "O Dia em que Lady Morreu": "São 12:30 em Nova York uma sexta / três dias após o Dia da Bastilha, sim / estamos em 1959 e estou no trem indo ao engraxate / pois vou saltar do trem das 16:19 em Easthampton / às 9:15 eu vou direto jantar / e nem conheço as pessoas que vão me dar de comer".

$\left[5^{\circ}\right]$ Ler poemas como esse ou o delicioso "A Um Passo Deles" é tentar acompanhar, em tempo real, a mente atenta $\mathrm{e}$ fantasista do poeta enquanto flana pela metrópole e a incorpora fragmentariamente.

$\left[6^{\circ}\right]$ Já "Versos para os Biscoitos da Sorte" é composto apenas de frases paratáticas inspiradas nas mensagens "positivas" de biscoitos da sorte de restaurantes chineses, satirizando seu tom de profecia.

$\left[7^{\circ}\right] \underline{O}$ livro traz também outros poemas representativos como "Autobiografia Literária", "O Amante", e "À Memória de Meus Sentimentos".

$\left[8^{\circ}\right]$ As traduções são de alto nível, recriando os poemas em português e as características linguísticas, os vários registros da poesia de $\mathrm{O}^{\prime} \mathrm{Hara}$, muitas vezes com ganhos.

$\left[9^{\circ}\right]$ Exemplo rápido: o penúltimo verso de "Avenida A", "but for now the moon is revealing itself like a pearl" é vertido como "mas por ora a lua se desnuda como uma pérola". Aqui, a própria linguagem simula, com sua dança de letras, o strip-tease lunar.

$\left[10^{\circ}\right.$ ] Os 25 poemas representam 4,9\% de sua obra (constam 510 peças na edição de seus poemas completos). Como dar conta, em poucas peças, de uma poesia que, além de profusa e frenética, é marcada por várias fases e estilos?

$\left[11^{\circ}\right]$ O livro tem o mérito de ser bilíngue (crucial em matéria de poesia), mas a colocação dos originais ao lado das traduções, e não no fim do livro, seria uma decisão editorial mais acertada.

$\left[12^{\circ}\right]$ Apesar de terem ficado de fora poemas essenciais e representativos, é uma iniciativa louvável em tempos de trevas: "estamos mesmo em apuros, esparramados / pés para cima apontando o sol, rostos / minguando na escuridão colossal".

Rodrigo Garcia Lopes

ESPECIAL PARA A FOLHA

Podemos observar a ocorrência de dois blocos textuais que consistem: na apresentação do livro, do autor e da poesia do autor (em negrito), configurando-se em uma sequência descritiva, sob o processo da aspectualização, na qual são atribuídas qualidades aos três. Lopes preocupou-se em apresentar as partes que compõem a obra: a quantidade 
de poemas, os títulos dos poemas que considera mais representativos, o cuidado com a apresentação em duas línguas, no original e em português. Ou seja, ele fez um retrato do que o leitor deve encontrar. É interessante perceber que, dos 12 parágrafos, apenas em dois $\left(1^{\circ}, 4^{\circ}\right.$, parte do $7^{\circ}$, do $9^{\circ}$ e início do $10^{\circ}$, sublinhados) pudemos identificar a ocorrência de descritiva com objetos de acordo. Nos parágrafos $2^{\circ}, 3^{\circ}, 5^{\circ}, 6^{\circ}, 8^{\circ}$, parte do $10^{\circ}$ e $11^{\circ}$, o resenhista utilizou figuras de linguagem para caracterizar o poeta e sua obra.

Identificamos a sequência argumentativa nos $11^{\circ}$ e $12^{\circ}$ parágrafos. A sequência argumentativa se dá na evidência de um ato argumentativo presente nos operadores "mas" e "apesar de" que contrapõem, sem muitos danos, a valoração positiva expressa no texto. Ou seja, a obra apresenta muitas qualidades positivas, mas existem duas características editoriais que não a fizeram merecer as "cinco estrelas". Na avaliação do resenhista, um livro de poesia, publicado no Brasil, cujo autor é americano deveria ser bilíngue, como de fato é, mas (operador argumentativo), o melhor seria se a editora publicasse os poemas em inglês ao lado da sua versão em português, facilitando a leitura ao mesmo tempo em que privilegia os poemas em sua versão original. Outro argumento é que, apesar (outro operador argumentativo) de os poemas que o resenhista considera essenciais e representativos estarem de fora da publicação. Ou seja, "mas" e "apesar de" revelam uma decisão editorial equivocada, ainda assim, a iniciativa de publicá-lo, no final, é considerada válida. A resenha em questão busca avaliar a obra e, para isso, se baseia tanto na apresentação de dados informativos (objetos de acordo) quanto na atribuição de características qualificadoras abstratas (objetos de desacordo). Ao ler a resenha, pela adjetivação positiva, o leitor recebe a mensagem de que vale ler a obra de O’Hara. É na atribuição de valores positivos ou negativos que o resenhista orienta o leitor e indica (ou não) a leitura do livro.

\begin{tabular}{|l|c|c|l|l|l|}
\hline & Argumentativa & $\begin{array}{c}\text { Expositiva/ } \\
\text { Explicativa }\end{array}$ & Narrativa & Descritiva & Dialógica \\
\hline $\begin{array}{l}\text { Quatro Cinco } \\
\text { Um }\end{array}$ & 6 & 5 & & 1 & \\
\hline Álvaro Lins & 12 & 12 & & & \\
\hline Ilustrada & & 12 & & \\
\hline
\end{tabular}

Tab. 2. Sequências predominantes

Os resultados nos permitem concluir que os críticos/resenhistas, após a análise das obras, procedem na orientação do leitor por meio da argumentação, direcionando a atividade verbal para a construção de um discurso com visão sobre o livro, sobre o autor e o tema. As composições apresentam características que tanto procuram modificar a visão do leitor sobre determinados aspectos da obra e do autor como também procuram fazer um desenho claro de ambos e do tema. O que faz das críticas do /lustrada e algumas 
da Quatro Cinco Um serem mais expositivas é o predomínio de comparações centradas no esclarecimento do que são ou não são as obras para os críticos/resenhistas. O que torna as críticas de Álvaro Lins predominantemente argumentativas é a constante proposição de teses e antíteses, próprias da argumentação. No entanto, a finalidade da crítica é oferecer uma avaliação e o que fica é a ideia de que foi construída pelo crítico/resenhista.

A necessidade de esclarecimento não implica, no entanto, em grau de verossimilhança entre enunciado e nível de evidência do objeto de realidade. A força argumentativa se desloca para a identidade discursiva. A força argumentativa vem da autoridade do enunciador cujo compromisso é com a crença na adequação da proposição à realidade (SEIXAS, 2009, p. 129). Na resenha jornalística a autoridade recai sobre o crítico/resenhista. Vejamos: das 36 composições selecionadas podemos afirmar que $90 \%$ dos que assinam as resenhas possuem, pela indicação de suas formações e funções profissionais, o saber que se entende necessário para orientar e indicar a leitura dos livros, requisito que lhes confere a autoridade para analisar, julgar e valorar as obras. Dentre os colaboradores do Ilustrada, encontramos resenhistas com vasta experiência no ramo editorial, especialistas em Literatura Comparada, jornalistas que atuaram em editorias de cultura, escritores e críticos literários. A partir de suas competências, a organização jornalística Folha de $S$. Paulo entende - e os seus leitores aceitam pela confiança em sua marca conceituada - que os colaboradores possuem credibilidade devido às suas experiências e imagens construídas no campo literário. A Quatro Cinco Um demonstra que a escolha dos resenhistas está relacionada aos conhecimentos que eles possuem sobre determinada área, livro ou respectivo autor. No caso do Correio da Manhã (RJ), os textos são assinados por Álvaro Lins, representante da crítica impressionista no Brasil, intelectual respeitado e influente em sua época, cujo texto não tem relação com o discurso do campo jornalístico, mas do campo literário, ao contrário das resenhas que, mesmo trazendo a assinatura do resenhista, estão submetidas à marca da organização jornalística.

O último critério, potencialidades do mídium, discute até que ponto as potencialidades das mídias influenciam na constituição de gêneros discursivos. A premissa é de que as mídias têm um lugar secundário, ou seja, em termos de gêneros discursivos jornalísticos, não é determinante na sua constituição, considerando que a resenha é um gênero discursivo consolidado (SEIXAS, 2009). As características discursivas da resenha mantêm-se seja no impresso, seja no digital. A base da resenha é o texto escrito, melhor acessado em papel. O único fator que pode colaborar não só com a resenha como também com a crítica literária, podendo marcar o retorno desta nos moldes tradicionais para um jornal, é o aproveitamento das potencialidades do espaço da mídia digital. Seria preciso, no entanto, cultivar um tipo de leitor disposto a ler longos parágrafos em uma tela de computador ou celular.

\section{Considerações finais}

A origem da resenha é uma consequência direta do surgimento do jornalismo moderno, decorrente de uma série de transformações político-socioeconômicas que 
influenciaram definitivamente a sociedade. A resenha jornalística, portanto, é naturalmente uma composição resultante de caraterísticas fundamentais do campo como atualidade, periodicidade e objetividade. Voltada para a divulgação e análise de obras literárias, artísticas e produtos culturais recém-lançados, é direcionada sempre para o que é atual e novo. Desse modo, difere da crítica literária, considerada uma composição do gênero literário. A resenha, portanto, é a crítica do jornal, a notícia sobre obras artísticas e produtos culturais da atualidade. A resenha, apesar de ter um propósito informativo, não deixa de ser tributária da crítica literária, veio dela e lhe toma emprestadas as características de análise, julgamento e valoração, conferindo-lhe o propósito de orientação. A resenha se apresenta em uma cena de enunciação jornalística. No entanto, ao invés de instituir a cena é a cena que a institui.

Nas 36 composições analisadas, com textos da década de 40 e contemporâneos, mostra-se a predominância da sequência argumentativa, já que são trechos formados por adjetivações dos objetos. A força argumentativa se desloca para a autoridade de quem assina cuja identidade discursiva é desenhada por lugar social, experiência, imagem pública no campo literário. Comparando-se impresso e digital, não há potencialidade que modifica o gênero, já que essa atividade necessita do texto escrito, adequado tanto ao impresso como ao website noticioso. Assim, os critérios de definição de gênero sustentam a nossa proposição de que a resenha publicada em jornal é uma composição discursiva pertencente ao campo jornalístico.

Lia Seixas é professora do Programa de Pós-Graduação em Comunicação e Cultura Contemporâneas da Faculdade de Comunicação da UFBA.

liaseixas@gmail.com

Emiliana Carvalho é mestre pelo Programa de PósGraduação em Comunicação e Cultura Contemporâneas da Faculdade de Comunicação da UFBA.

emiliana.carvalho@yahoo.com.br

\section{Referências}

ADAM, J. M. Les textes: types et prototypes. Paris: Nathan, 1992.

ANDERSON, C.W; BELL, E; Shirkly, C. Jornalismo Pós-Industrial: Adaptação aos novos tempos. In: Revista da Escola. Parceria com a Columbia Journalism Review, ano 2, n. 5, abr./mai./jun. 2013.

BONINI, A. Reflexões em torno de um conceito psicolinguístico de tipo de texto. D.E.L.T.A., v.15, n.2, p.301-318,1999. 
BOURDIEU, P. A economia das trocas simbólicas. São Paulo: Perspectiva, 2007.

COUTINHO, A. Da crítica e da nova crítica. Rio de Janeiro: Editora Civilização Brasileira S.A., 1957.

DEUZE, M; WITSCHGE, T. O que o jornalismo está se tornando. Tradução de Rafael Grohmann. In: Parágrafo, v. 4, n. 2, jul./dez. 2016. Cuiabá, Progresso Editora, 1957.

EAGLETON, T. Teoria da Literatura: uma introdução. 6. ed. São Paulo: Martins Fontes, 2006.

FRANCISCATO, C. E. A atualidade no jornalismo: bases para a sua delimitação teórica. 2003. $818 f$. Tese (Doutorado em Comunicação) - Faculdade de Comunicação, Universidade Federal da Bahia, Salvador.

GROTH, O. O poder cultural desconhecido: Fundamentos das Ciências dos Jornais. Petrópolis: Vozes, 2011.

GUERRA, J. O nascimento do jornalismo moderno - Uma discussão sobre as competências profissionais, a função e os usos da informação jornalística. In:Intercom XXVI, 2003, Belo Horizonte. Disponível em: http://www.intercom.org.br/papers/nacionais/2003/www/pdf/2003_NP02_guerra. pdf. Acesso em: 17 jun 2017.

GUTMANN, J. Formas do telejornal: um estudos das articulações entre valores jornalísticos e linguagem televisiva. 2012. Tese (Doutorado). Programa de Pós-Graduação em Comunicação e Cultura Contemporâneas, Universidade Federal da Bahia. Salvador, 2012.

MARQUES DE MELO, José. A opinião no Jornalismo Brasileiro. 2. ed. Petrópolis: Vozes, 1994.

NINA, C. Literatura nos jornais: a crítica literária dos rodapés às resenhas. São Paulo: Summus,2007.

SCHUDSON, M. As notícias como um género difuso: a transformação do jornalismo na contemporaneidade. In: Comunicação \& Cultura, n. ${ }^{\circ} 12,2011$, pp. 139-150.

SEIXAS, L. Redefinindo os gêneros jornalísticos: Proposta de novos critérios de classificação. Salvador: Labcom, 2009.

SEIXAS, L. Gêneros jornalísticos: partindo do discurso para chegar à finalidade. In: Intercom XXXII, 2009, Curitiba. 